THURSDAY，APRIL 29， I886

\section{FLOWERS, FRUITS, AND LEAVES}

Flowers, Fruits, and Leaves. By Sir John Lubbock, Bart., M.P., \&c. "Nature Series." (London: Macmillan and Co., I886.)

THE President of the Linnean Society sets a good example. Not many men, we suppose, have more onerous or more multifarious duties than he. He earns his leisure, little though it be, and he makes excellent use of it. Flowers, fruits, and leaves, to say nothing of insects and archæological investigations, supply him with the recreation he needs, provoke his observation, and stimulate his intelligence. More than that, they make him a propagandist. He is anxious to share with others the pleasure and relief he obtains from the study of Nature. To this end he descends from the Presidential chair to converse familiarly on the objects of his study, not only with those who are already in sympathy with him, but with those benighted Philistines whom perchance he may yet hope to gather into the fold. The substance of the book before us formed the basis of certain lectures addressed to popular audiences, and is well suited, with the accompanying illustrations, to arouse the attention of the indifferent and of that very large class of persons who go through the world with their eyes shut.

Two of the lectures, those on "Flowers," have been previously published. They contain references to the relationships between insects and flowers, to the visitations of the former to the latter, and other cognate matters with which the reading public has been familiarised. We need therefore only allude to the remaining chapters, treating of "Fruits and Seeds" and of "Leaves." The terms are throughout used in their popular and not in their strict technical acceptation, a circumstance which at once brings under notice the very different means by which the same effect or purpose is fulfilled. The general reader concerns himself far more with results than with the way in which they are brought about, and hence he sees no incongruity in grouping the winged flower-stalk of the lime, the "keys" of the ash or the maple, and the winged seed of the pine under one and the same heading.

Sir John humours this tendency. Probably he feels that the majority would be repelled by morphological disquisitions, genealogical dissertations, and transcendental speculations. These things come after. For the present the author dilates upon the form and appearance of the fruit and seed in relation to the necessities of their life and the purpose of their existence. He thus points out, on the one hand, the modifications and adaptations to secure adequate protection for the seed from the vicissitudes to which it is exposed, and, on the other, the divers means by which the dispersion of the seed is effected and its germination facilitated. Similarly, in the case of the leaves, the author discusses the probable causes of the exuberant variation met with in these organs. Whatever the cause, the result is doubtless consistent with the principle expressed by "the greatest happiness of the greatest number," the co-relations and adaptations met with secure the maximum of advantage Vol. xxxirr.-No. 86 I possible to each leaf with the least interference with the requirements of neighbouring leaves. It is not often we should be disposed to cite Mr. Ruskin as an authority on botanical matters, but in the fifth volume of his "Modern Painters" he has to some extent anticipated Sir John, and given some striking illustrations of the mutual adjustments between the several leaves on the same branch.

The protection possibly afforded by the close resemblance of one plant (unprovided with other means of defence) to another duly equipped with defensive armour was not thought of in pre-Darwinian days. Sir John Lubbock in the volume before us gives several illustrations of the phenomenon which, whether we accept the explanation or not, are very striking. Attention is also called to the primordial leaves which succeed to the cotyledons or seed-leaves. In many cases, as in conifers and in most compound-leaved plants, the form of these adolescent leaves differs widely from that of the adult foliage. From these circumstances the obvious inference is drawn that plants with lobed or compound leaves are derivatives from ancestors that had leaves of simpler type. The seedling plant in such cases is assumed to repeat the form and appearance of its ancestors. If this inference is taken in a general sense, and not made too exclusive in its application, it will meet with general acceptance. But we do not think that we are entitled to assume direct genetic connection in all such cases. Of necessity simple leaves must precede divided or compound ones. Similarity of conditions and requirements would bring about, in the case of archaic and of recent plants respectively, similarities of form without any necessary direct hereditary connection between the two.

A few slips may be mentioned for correction in the next edition; thus, it is hardly correct to describe the leaves of Desmodium gyrans as perpetually moving round (p. 49) ; Stael (p. I I4) should be Stahl; and the reference (at p. 93) to "Mr. Moore" requires further differentiation, as there are several Moores known to botanists. In this case Spencer Le Marchant Moore is probably intended.

We have said enough to show what varied sources of interest are opened up by Sir John Lubbock in this book. We trust that in future we may have further discussions of like nature from his pen, and we might suggest to him, as a complement to what he has here given us, a chapter on the significance of the various modifications of leafarrangement met with in Buds.

\section{MAXWell T. MASters}

\section{THE GEOLOGY OF PALESTINE}

Memoir on the Physical Geology and Geography of Arabia Petraa, Palestine, and Adjoining Districts. By Edward Hull, F.R.S. (Under the auspices of the Committee of the Palestine Exploration Fund. I 886.)

$\mathrm{MUCH}^{\mathrm{UCH}}$ heen written in recent years regarding the geology and natural history of that deeply interesting region which lies to the east of the Gulf of Suez, and includes the Basin of the Jordan River. Yet much still remains for further exploration, more especially in the way of more accurate detail and of connected analysis of the whole region. Recognising this deficiency of information, the Committee of the Palestine Explora- 